\title{
Introducing Journal of ES Energy \& Environment: Better Life, Beautiful World and Bright Future
}

\author{
Qinglong Jiang, ${ }^{1}$ Mansour Mortazavi, ${ }^{1}$ Jianli Wang, ${ }^{2}$ Yanan Liu, ${ }^{3}$ Zhaoxiang Wang, ${ }^{4}$ Wei Yu, ${ }^{5}$ Zhanhu Guo, ${ }^{6}$ and Bingyang Cao ${ }^{7 *}$
}

From the open land coal mining to the building of dam for hydropower, from the nuclear catastrophe to the crude oil spill, we have changed the environment tremendously. The energy, in any kinds of form, plays an irreplaceable role in the development of economy; the environment, where we are from and where we will be in, is the cradle of human civilization. ES Energy \& Environment, aiming for a Better Life/Beautiful World/Bright Future, is a peer-reviewed international journal for the publication of very high quality, ground-breaking research from across all areas of energy capture, conversion and storage, alternative fuel technologies and environmental science.

Keywords: Energy; Environment; Sustainability; Pollution

Accepted 19 October 2018

DOI: $10.30919 /$ esee $8 \mathrm{c} 156$

1986, early morning on April 26 $6^{\text {th }}$, an explosion woke up the people in the small city Pripyat. It also woke up the people's nuclear dream in the world. This city was in Ukraine and the name of the explosion was called Chernobyl nuclear disaster (Fig. 1a\&b). Over 30 years later, Pripyat is still a ghost town and over 200000 deaths were related to this worst nuclear disaster in the world. 24 years later, another explosion happened on the sea of Mexico Gulf. Over 3.2 million barrels of crude oil leaked in to Mexico Gulf and over 2500 square kilometre of sea has been polluted as shown in Fig. 1c\&d. The damage to the human being and the environment caused by these disasters cannot be measured simply with dollar. Of course, this is not the end of the story: 2010 , July $16^{\text {th }}$, Dalian, China; 2011,

${ }^{1}$ Department of Chemistry and Physics, University of Arkansas, at Pine Bluff, Arkansas 71601,USA

'School of Mechanical Engineering, Southeast University, Nanjing 211189, China

${ }^{3}$ School of Environmental Science and Engineering, Dong Hua University, Shanghai 201620, China

${ }^{4}$ Key Laboratory for Renewable Energy, Chinese Academy of Sciences, Beijing Key Laboratory for New Energy Materials and Devices, Beijing National Laboratory for Condensed Matter Physics, Institute of Physics, Chinese Academy of Sciences, P.O. Box 603, Beijing 100190, China

${ }^{5}$ School of Environmental and Materials Engineering, Shanghai Polytechnic University, Shanghai 201209, China

${ }^{6}$ Department of Chemical and Biomolecular Engineering, University of Tennessee, Knoxville, TN 37996, USA

${ }^{7}$ Key Laboratory for Thermal Science and Power Engineering of Ministry of Education, Department of Engineering Mechanics, Tsinghua University, Beijing 100084, China

*Email:jiangq@uapb.edu; mortazavim@uapb.edu; wangjianli@seu. edu.cn;liuyanan@dhu.edu.cn; zxwang@iphy.ac.cn; yuwei@sspu.ed u.cn; zguo10@utk.edu; caoby@tsinghua.edu.cn
March $11^{\text {th }}$, Fukushima, Japan.....

In the process of acquiring energy during the long history of human civilization, such as from the wood to coal and from the crude oil to nuclear energy, the issues of destroying the balance of environment never stop.

The quality of human life is fuelled by energy. "Tens of thousands of years ago, our ancestors started a fire with a flintstone or by drilling wood. It's at that moment, when human being started to request the energy from environment initiatively." During the long history of human civilization, different energy sources, no matter burning the wood or coal for cooking or hydroelectric energy or nuclear energy, have been utilized for the better of human being. According to a recent international energy outlook (IEO2018) report, ${ }^{2}$ driven by population growth and economic development, the annual energy demand will expand by $30 \%$ to about 270 trillion KWh by year 2040 . Today, energy is still derived primarily from use of fossil fuels (oil, coal and natural gas). The consequences of continued reliance on these fuels are well known: resource depletion and severe environmental impacts, examples include pollution, radiation, radioactivity, waste disposal, acid rain, stratospheric ozone depletion, global climate change, and etc. For a sustainable future, the challenge is to prevent or mitigate the negative consequences while also allowing for the continual improvement in human health protection and environmental quality.

Energy is essential for sustainable development. ${ }^{3}$ Energy sustainability involves processes and technologies for the harvesting of sustainable energy sources, their conversion to useful energy forms, utilizing sustainable materials, increasing efficiency, reducing environmental impact, improving socioeconomic acceptability, transport and storage. A large amount of progress in energy system has been made during the past few decades. For instance, a variety of sources of renewable energy have grown rapidly, ${ }^{4}$ including wind, solar, hydroelectric, tidal, geothermal and biomass, which become increasingly cost-competitive with conventional generation technologies. According to the recent report, ${ }^{5}$ the costs of solar photovoltaic electricity have come down by about $86 \%$, and wind by $67 \%$ since 


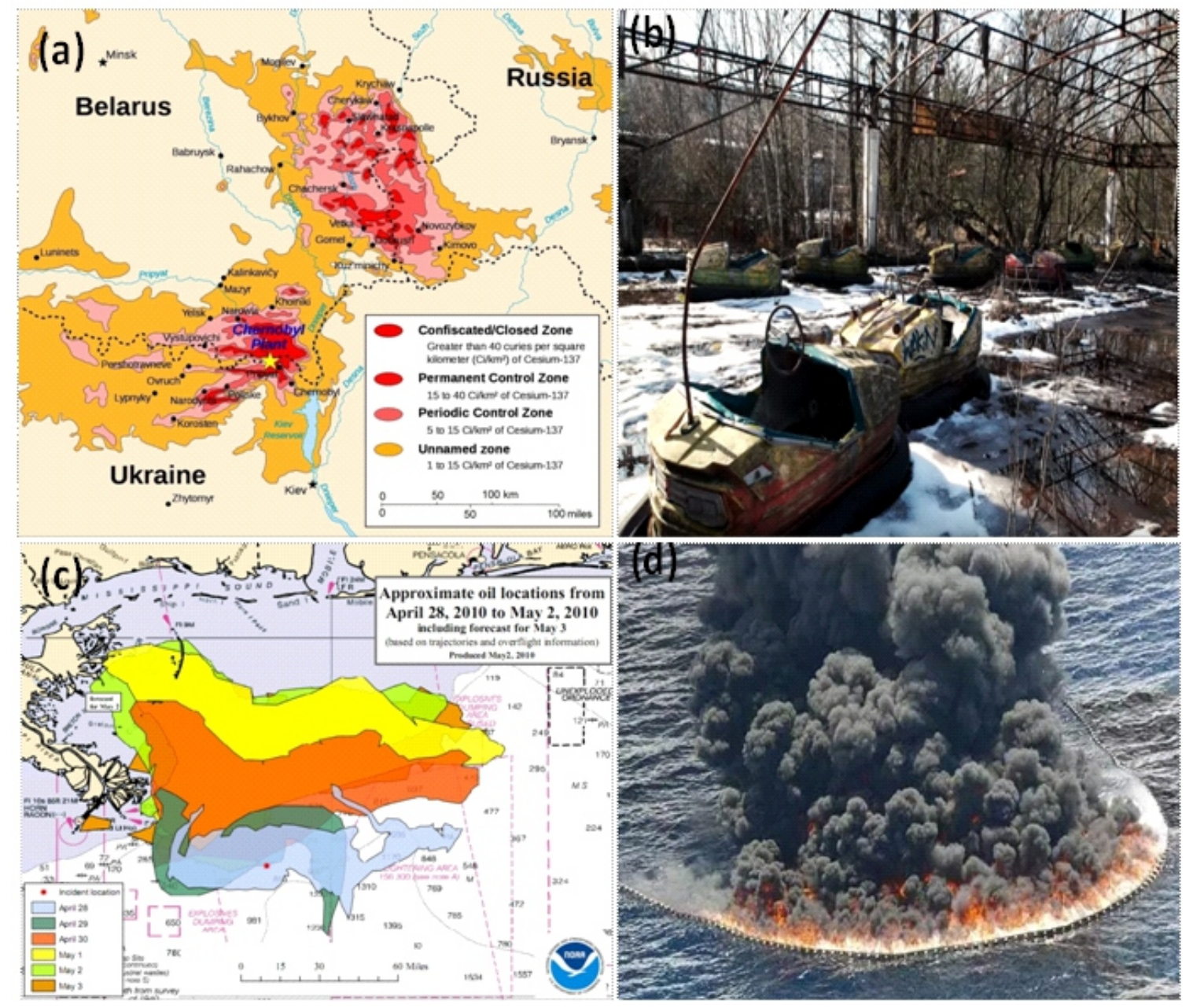

Fig. 1 a: A quarter century later after Chernobyl nuclear disaster; b: abandoned play ground; c: oil pollution range 6 days later after the explosion; d: Gulf of Mexico oil spill.

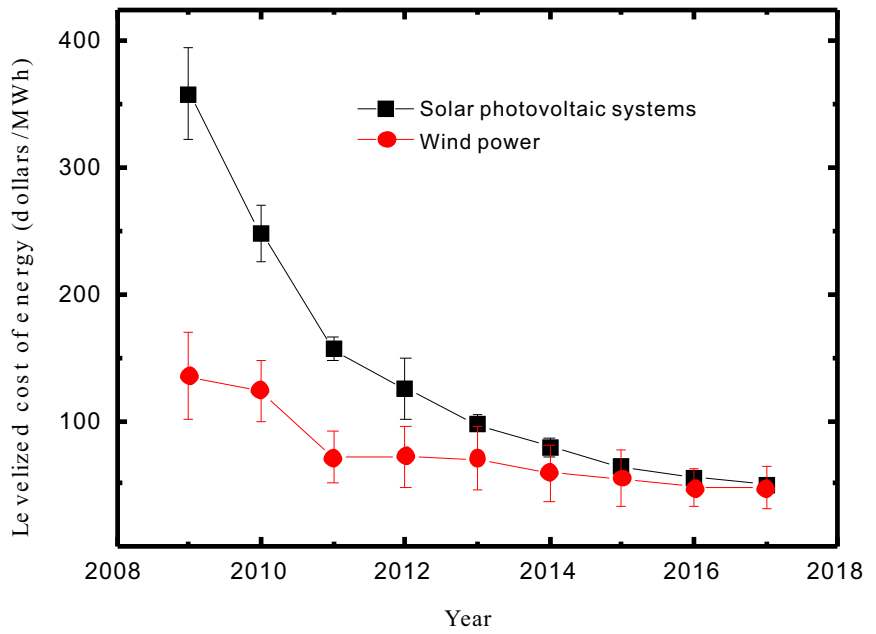

Fig. 2 Historical reduction of levelized cost of renewable energy from solar photovoltaic system and wind.

2009 (Fig. 2). Rapid expansion of electric vehicle significantly reduces the emission. Electric vehicles can convert about 59\%-62\% of the electrical energy from the electrical grid to motive energy, compared to about $20 \%-30 \%$ of the energy stored in gasoline to power at the wheels. Despite these advantages, electricity charging and storage, and the limited range are the main challenges, which are closely related to the battery technology. ${ }^{6,7}$ The lithium ion batteries, which have been widely used in portable electronics and electric vehicles, are finding bottlenecks difficult to break through, such as the shortage of lithium and cobalt, lack of electrode materials with sufficiently high specific capacity and energy density. Therefore, new types of secondary batteries are under development including solid state lithium batteries, lithium-sulfur batteries and even lithium-air (or oxygen) batteries to significantly increase the battery energy density, and secondary sodium $(\mathrm{Na})$, potassium $(\mathrm{K})$, and magnesium $(\mathrm{Mg})$ batteries to avoid the overuse of lithium. Another shift comes from the thermoelectric power generation, which can be used as a waste heat recovery system in automobile industry. ${ }^{8}$ Without sacrificing high conversion coefficient, the environmental-friendly and earth-abundant thermoelectric materials become popular, such as sulfur ${ }^{9}$ and silicide based materials. ${ }^{10}$ All these sustainable energy systems call for a multi-disciplinary approach that combines the physical, chemical, engineering, material, social and environmental sciences, thus providing us a broad space of investigation and innovation.

The environmental management and protection also play an 


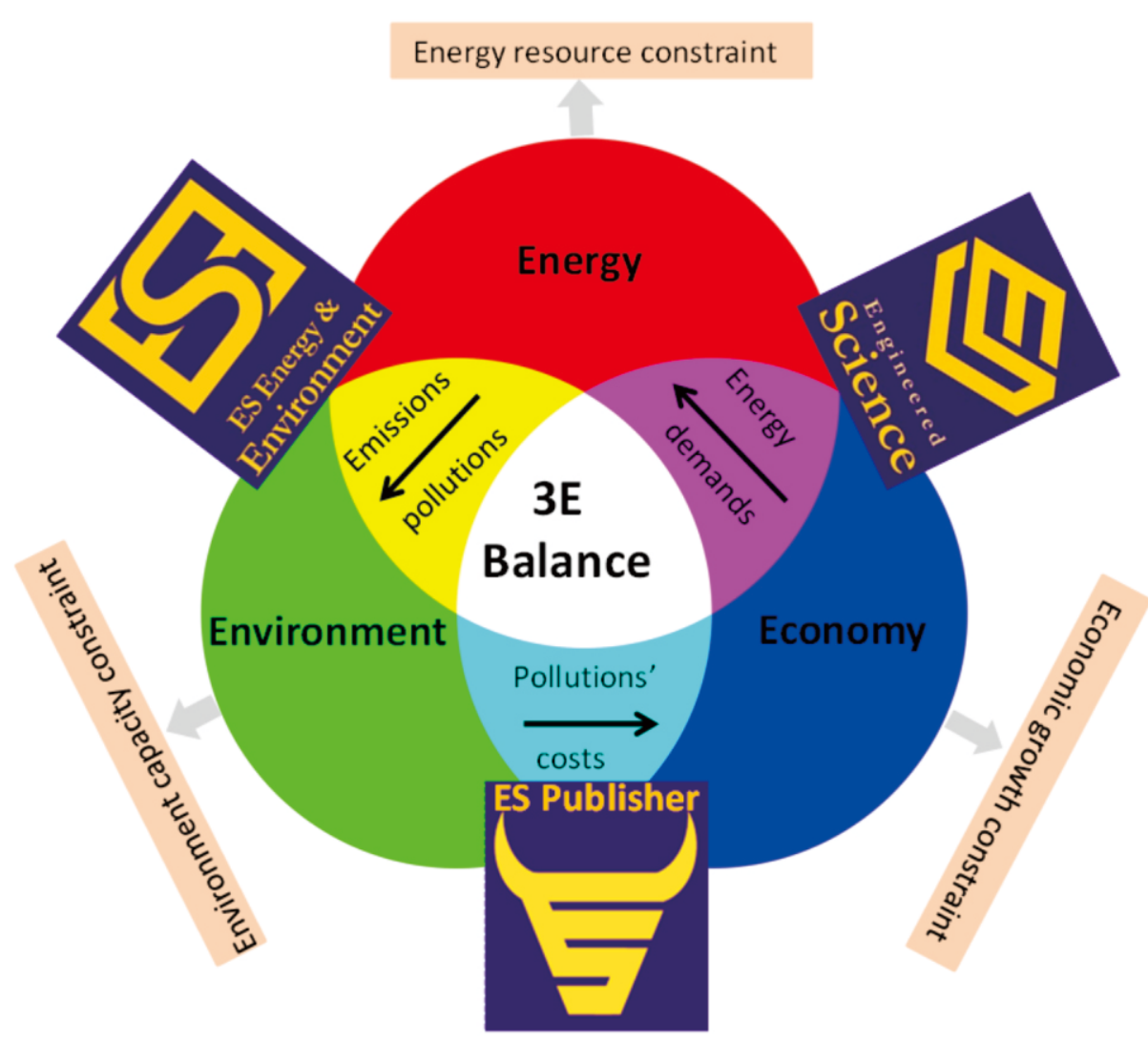

Fig. 3 The concept of $3 \mathrm{E}$ balance. ${ }^{1}$

important role in the quest for sustainable development. The problems of environmental pollution, fossil-fuel depletion and resources shortage have driven intensive efforts towards finding more emerging contaminants, monitoring them in trace levels, studying their possible negative effects and developing more sustainable treatment techniques. Ecological, biological or microbiological treatment processes are always the ways to minimize energy and carbon footprint of human activities. Energy and resources contained in the polluted environment should be recycled to attenuate the worldwide resources shortage.

As shown in Fig. 3, the concept of $3 \mathrm{E}$ balance indicates the relationship between Environment, Energy and Economy. 3E are a mutual balance, in which economy development cannot sacrifice the environment by greedily acquiring the energy. A damaged environment, including air/water/soil, cannot support the growth of economy. Environmental friendly, affordable, greener energy boosts the economy growth.

ES Energy \& Environment is a peer-reviewed international journal for the publication of very high quality, ground-breaking research from across all areas of energy capture, conversion and storage, alternative fuel technologies and environmental science. It is aiming to get clearer and greener energy for a Better Life, Beautiful World and Bright Future.

\section{References}

1.Q. L. Jiang, W. Yu, A. Mosleh, D. Wang, X. Tu, Y. Liu, Z. Guo, G. Wangila, B. Cao, C. Liu and B. J. Ewards, Eng. Sci. , 2018, 3, 1-4.

2. www.eia.gov/outlooks/ieo/

3. M. Munasinghe, Int. J.Sust. Dev., 2002, 5, 125-182.

4. J. Newman, C. A. Bonino and J. A. Trainham, Annu. Rev. Chem. Biomol. Eng., 2018, 9, 153-174.

5.www.lazard.com/perspective/levelized-cost-of-energy-2017/

6. A. Mahmoudzadeh Andwari, A. Pesiridis, S. Rajoo, R. MartinezBotas and V. Esfahanian, Renew. Sust. Energ. Rev., 2017, 78, 414430.

7. L. Yan, H. Wang, D. Huang and H. Luo, Eng. Sci., 2018, 1, 4-20.

8. L. E. Bell, Science, 2008, 321, 1457-1461.

9. H. Wang, J. Wang, X. Cao and G. J. Snyder, J. Mat. Chem. A, 2014, 2, 3169-3174.

10. W. Liu, K. Yin, Q. Zhang, C. Uher and X. Tang, Natl. Sci. Rev, 2017, 4, 611-626.

11. S. Chu and A. Majumdar, Nature, 2012, 488, 294-303. 